\title{
A CRÍTICA DE PROCESSOS NA PERSPECTIVA DA CONTINUIDADE DA CRIAÇÃO NO ESPECTADOR
}

THE PROCESSES CRITICISM IN THE CONTINUITY PERSPECTIVE OF THE

CREATION IN THE SPECTATOR

Patrícia Dourado

PUC-SP

Paula Martinelli

PUC-SP

Wagner Miranda Dias

PUC-SP

Resumo: Um dos temas caros à crítica de processos, conforme proposta por Cecilia Almeida Salles, no âmbito do Programa de Pós-Graduação em Comunicação e Semiótica da PUC-SP, é o das práticas comunicativas. Sob este viés, a teórica aponta para a criação como "uma ten-dência para o outro em vários sentidos" (SALLES, 2002, p. 68). Aqui, trazemos um estu-do que tem o potencial de revelar algumas dimensões dessas práticas, no que diz respeito especialmente ao desejo do encontro com o espectador. Além da crítica de processos de Salles, outros teóricos colaboram para essa investigação, entre eles, Gilbert Simondon, Jacques Rancière, Georges Didi-Huberman, Vincent Colapietro e Charles Sanders Peirce, esses dois últimos em diálogo direto com Salles. Trata-se de um esforço que exemplifica os trabalhos multidisciplinares desenvolvidos no Grupo de Pesquisa em Processos de Cri -ação (CNPq) da PUC-SP, em diferentes linguagens e sob diversos enfoques da criação. Acreditamos que, ao assumir a obra como catalisadora de fenômenos culturais, agregados por um sujeito, nos afastamos da "tentação de compreender os processos criativos na rela-ção direta entre o fato vivido e a obra ficcional” (SALLES, 2006, p. 70), e é isso o que buscamos aqui, tomando como elo a relação com o espectador e o referencial da crítica de processos.

Palavras-Chave: crítica de processos; redes de criação; práticas comunicativas; sujeitos; criação.

Abstract: One of the main themes to the theory of creation processes, as proposed by Cecilia Al-meida Salles, is that of communicative practices. Under this bias, the author points to cre-ation as "tendency towards the other in several ways" (SALLES, 2002, p. 68). Here, we bring a study that aims to show some dimensions of these practices, especially in regards to the desire of encounter with the viewer. In addition to Salles' criticism of processes, other theorists collaborate in this investigation - among them Gilbert Simondon, Jacques Rancière, Georges Didi-Huberman, as well as Vincent Colapietro and Charles Sanders Peirce, with whom Salles stablishes dialogue. It is an effort that exemplifies the multidisci-plinary works developed by the Research Group on Processes of Creation (CNPq) at PUC-SP, in different artistic languages and under several approaches to creation. We believe that by taking the work of art as a catalyst for cultural phenomena, aggregated by subject, we take distance from the "temptation to understand the creative processes in the strict relation between lived fact and the fictional work" (SALLES, 2006, p. 70), and this is what we seek here, choosing as starting point the relations between author and viewer.

Keywords: theory of creation processes; creation networks; communicative practices; subject; crea-tion. 


\section{Introdução}

Ao iniciarmos esta reflexão, é importante pontuar que esta é uma pesquisa que surge do Grupo de Pesquisa em Processos de Criação, ligado ao Programa de Estudos Pós-Graduados em Comunicação e Semiótica da Pontifícia Universidade Católica de São Paulo (PEPGCOS/PUC-SP). No âmbito do grupo, circulam modos de pensar gerais em relação aos processos criativos, tendo como base a multiplicidade de olhares sobre os diferentes objetos de estudo, de diferentes áreas, que se dão nas discussões do grupo, à procura de recorrências e nexos que apontem, ao mesmo tempo, tanto para as generalidades como para as especificidades de cada processo.

Formado por pesquisadores que investigam processos de criação em linguagens diversas, o grupo tem ancoragem na crítica de processos, criada por sua coordenadora Cecilia Almeida Salles, em diálogo com a semiótica, tal como formulada por Charles Sanders Peirce, e que considera em seus conceitos o sujeito e a função comunicativa da criação.

A abordagem da fenomenologia peirceana aponta para as perspectivas de fluxo e de movimento, o que refuta o cartesianismo e a oposição sujeito x objeto. Tratamos, assim, de percepções. "Peirce nos livrou da crença de que o sujeito é algo isolado, envolto numa aura de autonomia, senhor de pensamentos sob seu perfeito controle" (SANTAELLA, 2012, p. 116).

Sem começo e sem fim, esse corpo guarnecido de intelecto age, cria e transforma, enquanto é, ele mesmo, objeto - no sentido gramatical - e transformado. Ou seja, entendemo-nos e tornamo-nos autoconscientes enquanto percebemos o mundo, em interação - sensível e cognitiva - com o outro e com os fenômenos em geral, conforme Peirce desenvolve nos conceitos de primeiridade, secundidade e terceiridade ${ }^{1}$.

Com isso, temos respaldo teórico para tratar a criação como fenômeno catalisador de percepções, sendo o próprio projeto poético a busca pela materialização das transformações perceptivas no contato do sujeito com o mundo, com o outro e consigo mesmo. Estamos assim em pleno campo das redes de criação (SALLES, 2006), das interações entre/intra universos semânticos; campo esse que descarta a suposta verticalidade na relação entre autor e espectador e que propõe a ideia de obra enquanto substrato de mediação.

Neste artigo, abordaremos então a criação como fenômeno perceptivo, situando os sujeitos - autor e espectador - nessa condição ativa e transformadora.

\section{Conceitos de sujeito e de criação: a criação como fenômeno perceptivo}

De partida, é preciso esclarecer o conceito de sujeito aqui trazido. O sujeito é aquele moldado pelos hábitos que o precedem, expressão de gestos imemoriais, resultado da cultura e, simultaneamente, intervenção na cultura.

Esse indivíduo ambíguo, híbrido e complexo em nada se aproxima da subjetividade ideal, estanque. Esse conceito acerca do sujeito encontra eco em diversos pensadores contemporâneos. Entre eles, Edgar Morin, Gilbert Simondon e Vincent Colapietro.

Segundo Simondon, por exemplo, não existe

\footnotetext{
1 "Parece, então, que as verdadeiras categorias da consciência são: primeira, sentimento, a consciência que pode ser incluída com um instante de tempo, consciência passiva de qualidade, sem reconhecimento ou análise; segunda, consciência de interrupção no campo da consciência, sentido de resistência, de um fato externo, de alguma outra coisa; terceira, consciência sintética, ligação com o tempo, sentido de aprendizagem, pensamento". (CP, 1.377, apud IBRI, 1992, p. 14).
} 
um indivíduo acabado e pronto, existem processos de individuação. O defasamento de si acontece continuamente e, assim, o sujeito se define sempre na relação.

A concepção de ser sobre o qual repousa este estudo é a seguinte: o ser não possui uma unidade de identidade, que é a do estudo estável em que nenhuma transformação é possível, o ser possui unidade transdutora, isto é, ele pode defasar-se em relação a si próprio, ultrapassar a si próprio de um lado e de outro de seu centro. (SIMONDON, 2003. p. 110).

Para Simondon, o processo de individuação é de emergência de singularidades, de transformação, pois não existe um indivíduo acabado e pronto, o que encontra afinidade com Morin, quando este trata do sujeito como ser complexo, inserido e ator do processo cultural.

As sociedades só existem e as culturas só se formam, conservam, transmitem e desenvolvem através das interações cerebrais/espirituais entre os indivíduos. A cultura, que caracteriza as sociedades humanas, é organizada/ organizadora via o veículo cognitivo da linguagem, a partir do capital cognitivo coletivo dos conhecimentos adquiridos, das competências aprendidas, das experiências vividas, da memória histórica [...]. (MORIN, 2011, p. 19).

E, por isso, o sujeito é processual. Para Peirce, "[...] todo estado de consciência é uma inferência: de modo que a vida não é senão uma sequência de inferências ou um fluxo de pensamentos" (PEIRCE, 2010, p. 306). As relações com o mundo criam as redes, proposições coletivas e, a partir dessa percepção, se articula a ideia do outro e de si mesmo. Assim como o sujeito, o percebido segue a ordem do instável: tudo está, nada é. Colapietro, ao construir o conceito de self, nos diz que
Para Peirce, o self é um signo. A forma como ele elabora as implicações desta visão sugere uma estrutura ampla para o entendimento da subjetividade humana. [...] Além disso, Peirce insiste em que uma pessoa não é completa enquanto ele ou ela for individual: a pessoa é essencialmente um possível membro de sociedade (5.402 n2). Não apenas o sujeito é um possível membro de comunidade; a pessoa como sujeito tem a própria forma de comunidade (5.421). (COLAPIETRO, 2014, p. 84).

Assim, encontramos amparo para afirmar que nenhum processo é individual, o self é sujeitocomunidade. Se a constituição subjetiva é coletiva, assim se dão, também, os processos de criação. Salles estabelece vínculos teóricos fundamentais ao transpor as ideias de Morin e Colapietro para o contexto da criação com o conceito de "redes de criação". A teórica assinala que inexiste a produção isolada, a ideia primeira, afirmando que a ancestralidade dos processos e a intricada trama de relações entre artista, interlocutores e contexto é responsável por trazer a coletividade para toda produção.

A partir dessas questões, vejo os agentes em criação em meio à multiplicidade de interações e diálogos - sujeitos constituídos e situados - que encontram modos de manifestação em brechas que seus filtros mediadores conquistam. O próprio sujeito tem a forma de uma comunidade; a multiplicidade de interações não envolve absoluto apagamento do sujeito e o locus da criatividade não é a imaginação de um indivíduo. Proponho, assim, um conceito de autoria, exatamente nessa interação entre o sujeito e os outros. [...] Trata-se de um conceito de autoria em rede. (SALLES, 2017, p. 39-40).

Isso posto, entendemos que esse sujeito-comunidade é compatível com o sinequismo sígnico: temos que todo signo tende a gerar outros tantos em progressão infinita e em relação in- 
ferencial. O sujeito-autor, portanto, ele mesmo signo e em rede, encontra-se em um processo que o altera e o ultrapassa. Salles indica a ponte entre autoria e sinequismo quando nos diz que

Essa abordagem de autoria dialoga, de modo explícito, com o conceito de criação, desenvolvido em nossa discussão, que se sustenta em seu aspecto relacional. Como dissemos, é importante pensar no ato criador como um processo inferencial, no qual toda ação, que dá forma ao novo sistema, está relacionada a outras ações de igual relevância, ao se pensar o processo como um todo. Sob esse ponto de vista, qualquer momento do processo é simultaneamente gerado e gerador. (2006, p. 152).

As interações que visam à interface artística são, portanto, de natureza comunicativa, cultural, coletiva e contínua.

\section{Criação, comunicação e transformação no encontro com o outro}

Ao tratarmos o sujeito e a criação nesses termos, temos explícito seu caráter comunicativo e transformador. Transpondo essa reflexão para o atual contexto acadêmico, marcado por discussões sobre a teoria da imagem, podemos destacar a contribuição de Rancière. Quando o teórico aborda os três modos de ser das imagens - nua, ostensiva e metamórfica - ele coloca implícito como ponto de distinção entre eles o tipo de interação entre autores e espectadores.

Sobre as imagens nuas, ele nos diz que aquilo que as une é "o testemunho de uma realidade a qual comumente se admite que não tolera outra forma de apresentação" (2012, p. 32). Já a imagem ostensiva é descrita como "a presença obtusa que interrompe histórias e discursos e se torna a potência luminosa de um face a face" (Ibid., p. 33); por fim, a imagem metamórfica joga com a "ambiguidade das semelhanças e a instabilidade das dessemelhanças" (Ibid., p. 34), operando uma "redisposição local, um rearranjo singular das imagens circulantes” em uma "dupla metamorfose [...]: a imagem como cifra da história e a imagem como interrupção" (Ibid., p. 34 e 35). É importante ressaltar que esses três regimes de interação mediados pela imagem não aparecem isoladamente.

Imagem nua, imagem ostensiva e imagem metamórfica: três formas da imagéité, três maneiras de vincular e desvincular o poder de mostrar e o poder de significar, o atestado da presença [...]. Ora, é significativo que nenhuma das três formas assim definida possa funcionar encerrada em sua própria lógica. Cada uma delas encontra em seu funcionamento um ponto de indecibilidade que a obriga a tomar alguma coisa emprestada das outras (Ibid., p. 36, grifos nossos).

Ou seja, não estamos falando de uma classificação que encerra a discussão sobre determinada imagem, mas do reconhecimento de diferentes formas de mostrar e de interpretar e, ainda, da indeterminância e do movimento como constantes. Podemos, portanto, entender que a criação tem finalidade expressiva e que o processo, posto em marcha por esse sujeito sobredeterminado e em rede, se desenrola em direção à interlocução, ao dar-a-ver e à transformação.

Pensemos nas interações responsáveis pela geração de novas ideias ou possibilidades de obras. O processo inferencial destaca as relações, como vimos; no entanto, para compreender melhor o ato criador, interessa-nos a natureza destes vínculos, isto é, do que são feitas as inferências, suas tessituras. De um modo geral, poderíamos observar essas inferências sob o ponto de vista da transformação (ou transformações) que opera(m), na medida em que as interações, como ações recíprocas, modificam 
o comportamento ou a natureza dos elementos envolvidos (Morin, 2002b, p. 72). Essas modificações nos levam a um novo campo semântico que nos parece ser de grande importância: dar nova forma, ou feição; tornar diferente do que era; mudar, alterar, modificar, transfigurar, converter, metamorfosear. (SALLES, 2006, p. 34).

A criação, portanto, não se encerra na autoria; as relações inferenciais seguem, em transformação, rumo à contemplação; o espectador participa do ato criador. E esse movimento do dar-a-ver faz parte do pensamento criativo. Tudo aquilo que é feito, na forma e no tempo em que é feito, assim o é para ser visto, pois "O processo de criação mostra-se, também, como uma tendência para o outro. Está em sua própria essência a necessidade de seu produto ser compartilhado" (SALLES, 2011 p. 48). Por isso, a intenção de publicação de uma obra passa a ser tão relevante para os processos de criação quanto o percurso feito até que ela seja publicada, posto que lhe é parte integrante. A tentativa, o ensaio e o experimento são conduzidos como parte de um processo que visa a uma interface comunicativa. Mesmo o descarte, o erro e o acidente, nesse sentido, são também orientados à publicação. Por publicação entendamos como tornar público, em diálogo, diante de um interlocutor.

O encontro mediado pela obra é, portanto, comunicativo, o que não significa, contudo, que resultados sejam controláveis. A necessidade de dar-a-ver e de contemplar, por sua vez, não implica em antevisão, em uma premonição determinante que elimina erros, acasos e memórias involuntárias, mas trata-se da força motriz que coloca em marcha o processo de criação, em ambas as extremidades - autoral e contemplativa - com todas as suas incertezas.

William Kentridge, em recente entrevista, deu uma declaração que explicita como ele, artista, percebe o jogo entre dar-a-ver e contemplação como elemento que orienta suas práticas:

Se você dá a mesma fotografia a duas pessoas, cada uma dirá coisas diferentes. Isso significa que só podem estar falando de si mesmas. Não veem a fotografia, veem a si mesmas. Por isso uma das funções do artista é lembrar o espectador que quando olha uma obra não está vendo uma verdade, mas uma projeção². (2018, s.p.).

Em outras palavras, a existência do espectador está presente na criação, plasmada no processo autoral do dar-a-ver. A existência do autor, igualmente, se faz presente no ato cognitivo e contemplativo de fazer elaborações, de interpretar os feitos de outras pessoas. O si mesmo e o outro fazem parte dessa projeção que orienta o criar e o contemplar. Por isso, as posições autor e espectador não são estanques e se constroem, também, na própria inversão de papéis. Existe uma troca viva que situa a criação e a contemplação nos trânsitos em rede.

Colapietro, em evento realizado em São Paulo, em novembro de 2017, sob o título de $17^{\circ}$ Encontro Internacional sobre Pragmatismo, trouxe em sua fala a prolífica discussão sobre a leitura diante dos arquivos peirceanos: "reading is a form of dreaming, albeit a very distinctive or singular form, since dreaming in this case is under the influence of authorial instruction" 3 .

Atribuímos, por isso, a essa troca - de instruir e de ler - a qualidade interpretativa e assumimos que ela define a articulação entre imaginação e lógica que ocorre quando autor e espectador se deparam com a imagem, um complexo apa-

2 Disponível em: <https://brasil.elpais.com/brasil/2017/12/26/eps/1514287197_612651.html>. Acesso em: 10 mar. 2018.

3 Em tradução livre: "A leitura é um tipo de sonho, embora seja uma forma muito distintiva ou singular, já que o sonho neste caso está sob a influência da instrução autoral”. 
rato material que condensa as transformações perceptivas do processo de produção e serve de marco materialmente disposto na cadeia da progressão sígnica. A partir dela, transformações perceptivas continuam a ocorrer naquele que olha.

O querer ler e interpretar signos oferecidos à contemplação coloca em curso um esforço cognitivo que naturalmente aciona as instâncias perceptivas e reminiscências do inconsciente. Ler, portanto, é transformar e atualizar - a começar por si próprio - acatando as instruções autorais como gatilhos de seus próprios mecanismos; é aceitar a provocação para um confronto de ideias, memórias, universos semânticos, contextos, fatos e sensações que já perdemos de vista e que nos surpreendem na forma de memórias involuntárias.

Vamos a exemplos dessa formulação em diferentes linguagens. O processo de trabalho com o roteiro no cinema, por exemplo, experimenta características muito importantes do processo criativo da leitura de que falou Colapietro (2017). A leitura é ela mesma um processo criativo:

Todo filme é, pois, o resultado de uma sucessão de etapas, imateriais e materiais, nas quais as imagens tomam forma: nesse processo, o "cinema mental" da imaginação desempenha um papel tão importante quanto o das fases de realização efetiva das sequências, de que a câmera permitirá o registro e a moviola a montagem. Esse "cinema mental" funciona continuamente em nós - e sempre funcionou, mesmo antes da invenção do cinema - e não cessa nunca de projetar imagens em nossa tela interior. (CALVINO, 2008, p. 99).

Flávio Desgranges, ao falar da criação no teatro, também situa o espectador:

As estratégias adotadas pelos artistas em processo são definidas a partir da relevân- cia e da pertinência de seus interesses, de questões e procedimentos, mais ou menos coordenados, que os criadores propõem para si mesmos, e que podem estar intimamente relacionadas com as inquietações, os riscos e desafios que os artistas sugerem ao público posteriormente. [...] Esta analogia do mito de Édipo com o processo de investigação que se lança (e é lançado) ao espectador em ato de leitura - semelhante ao do artista em ato de criação -, nos possibilita pensar sobre a necessária implicação do sujeito em processo criativo em face das questões que o atormentam. (DESGRANGES, 2017, p. 23 e 27)

É pela pesquisa que o autor tenta satisfazer a própria busca enquanto, simultaneamente, testa formas de suscitar a busca alheia. Esclarece-se, contudo, que não se trata de um exercício das teorias da recepção, posto que o direcionamento proposto pelo autor não tem contornos que coincidem exatamente ao sentido da obra.

Temos dois selfs em contato mediado pela obra, configurando com isso um exercício de identidade e de alteridade - por meio daquilo que criamos e lemos, do conhecimento que transformamos, em interação, estamos em contato com formas de subjetivação, entre elas as nossas e as do outro.

$\mathrm{Na}$ imagem de arte, qualquer que seja a linguagem pela qual ela se materializa, o dar-a-ver é marcado pelo escape à obviedade, bem como pela existência de iscas à imaginação alheia. Disso resulta, por exemplo, a ineficiência das tentativas de atribuir-lhes determinado sentido, sobre o que Didi-Huberman nos fala:

[...] o conteúdo se dispersa florescendo, espaIhando-se por toda parte, e a "essência" só se fixa na matéria nonsensical do significante. 0 que impede de abreviar a imagem ou retê-la em qualquer caixa que seja. Pois a imagem retida em caixa - a da Ideia, por exemplo - é como água morta, água privada de sua capacidade de transbordar. (DIDI-HUBERMAN, 2013, p. 232). 
O que transborda é aquilo que está além do autor e de suas instruções. É o espectador que tem o poder de fazer a imagem - verbal, cênica, pictórica, fotográfica etc. - exceder o universo autoral e de, a partir de seu próprio universo semântico, atualizá-la - com seus sonhos, memórias e imaginações - realizando sua potência.

Colocando as ideias assim, fica evidente que os processos de criação não são estanques à etapa prévia à publicação. A imagem, obra, um gesto inacabado (SALLES, 2011), segue como signo em progressão e, nesse sentido, o espectador também participa do criar, e dá continuidade à criação ao interpretar e participar do jogo entre identidade e alteridade.

\section{Considerações finais}

É, portanto, a complexidade de escolhas autorais - de linguagem, procedimento, forma, estética e apresentação - que provoca a atividade criativa do espectador. Temos a transição do universo autoral, com toda sua potência interpretativa realizada em obra, para o universo do espectador, no qual essa potência será atualizada. São incontáveis os encontros críticos que o espectador pode ter com a mesma imagem ao longo dos anos - e, consequentemente, os diferentes sentidos que cada um deles produzirá.

Pensamento e criação, enquanto esforços de produção sígnica e de formas de subjetivação, são movimentos; signos e ideias são gerados e geradores ao longo dos processos perceptivos e cognitivos. 0 valor da incerteza, do indeterminado e das surpresas que se revelam durante o processo é combustível da atividade criadora, seja no ato de produção ou de contemplação.
Concluímos que a experiência do processo de criação é inacabada e constituída em duas dimensões: a do autor, que negocia com as linguagens para transformar a imagem em materialidade; e a do espectador, que participa da constituição da imagem em sua continuidade sígnica. Não há porque, então, desconsiderarmos a autoria ou a contemplação nas discussões sobre o processo de criação. Ao contrário, elas são as responsáveis por esse encontro mediado pela imagem.

\section{Referências}

CALVINO, Ítalo. Visualidade. In: __-_. Seis propostas para o próximo milênio. São Paulo: Companhia das Letras, 2008.

COLAPIETRO, Vincent. Peirce e a abordagem do self: uma perspectiva semiótica sobre a subjetividade humana. São Paulo: Intermeios, 2014.

DESGRANGES, Flávio. A interferência dos processos de criação nos modos de recepção artística: percursos de um pretérito imperfeito. In: DESGRANGES, Flávio; SIMÕES, Giuliana (Orgs.). O ato do espectador. São Paulo-Florianópolis: Hucitec, 2017.

DIDI-HUBERMAN, Georges. Diante $d a$ imagem. Trad. Paulo Neves. $1^{\text {a }}$ ed. São Paulo: Editora 34, 2013.

MORIN, Edgar. O método 4: as ideias. Habitat, vida, costumes, organização. Porto Alegre: Sulina, 2011.

PEIRCE, Charles Sanders. Semiótica. São Paulo: Perspectiva, 2010.

RANCIĖRE, Jacques. O destino das imagens. Trad. Mônica Costa Netto. $1^{a}$ ed. São Paulo: Contraponto, 2012.

SALLES, Cecilia A. Redes da criação: construção da obra de arte. Vinhedo: Horizonte, 2006. 
Arquivos da criação: arte e curadoria. Vinhedo: Editora Horizonte,2010.

Gesto inacabado: processo de criação artística. $5^{a}$ ed. São Paulo: Intermeios,2011.

Processos de criação em grupo: diálogos. São Paulo: Estação das Letras e Cores, 2017.

SIMONDON, Gilbert. A gênese do indivíduo. Tradução: Ivana Medeiros. In: Cadernos de subjetividade: o reencantamento do concreto. São Paulo: EDUC/Hucitec, 2003. 